\title{
El consumo de medios de comunicación y la publicidad por parte del inmigrante latinoamericano en la Comunidad de Madrid
}

\section{Media and Advertising Consumption on the Part of the Latin American People in the Community of Madrid}

\author{
Nuria Villagra García. Universidad Complutense de Madrid \\ Sonia Carcelén García. Universidad Complutense de Madrid \\ Belén López Vázquez. ESIC, adscrito a Universidad Rey Juan Carlos \\ Ana Sebastián Morillas. Universidad de Valladolid \\ Recibido: 4-V-2009 - Aceptado: 26-VI-2009 \\ Resumen:
}

El incremento de la población inmigrante en España en los últimos años ha contribuido a la aparición de medios específicos dirigidos a este colectivo. Este artículo se centra en el estudio del consumo de medios de los latinoamericanos que residen en nuestro país, así como su percepción de la publicidad aparecida en los distintos soportes. El planteamiento metodológico de la investigación está basado en un enfoque cualitativo mediante entrevistas en profundidad a expertos y grupos de discusión. Los inmigrantes latinoamericanos combinan el consumo de medios generalistas y étnicos, por lo que es necesaria una adecuada planificación para conectar eficazmente con este público.

Palabras clave:

Inmigrantes latinoamericanos, consumo de medios, publicidad.

Abstract:

The increase of the foreign population in Spain in the last several years has contributed to the emergence of specific media for this group. This article focuses on studying the immigrant Latin American peoples' media consumption as well as their perception of advertising in different media. The methodological approach used is markedly qualitative based on in-depth interviews with different professionals and focus-groups. Since Latin American immigrants consume both general and specific media, correct planning is needed to connect effectively with this target.

Key Words:

Latin-American Immigrants, Media Consumption, Advertising. 


\section{Introducción}

El consumo de medios por parte de los inmigrantes que residen en España está relacionado con el importante incremento de población extranjera que nuestro país ha experimentado en los últimos años y que, según los datos que ofrece el Instituto Nacional de Estadística (INE), en el Padrón Municipal del año 2008 se sitúa en 5268.762 millones de habitantes empadronados, lo que supone que un 11,41\% de la población residente en España es de origen extranjero. Este crecimiento de población ha contribuido al nacimiento y evolución de un gran número de medios dirigidos a inmigrantes de diferentes nacionalidades que se distribuyen en las principales ciudades españolas.

Un análisis del colectivo de inmigrantes residentes en la Comunidad de Madrid, que representa el 19,08\% respecto al total de la población empadronada en dicha Comunidad (Observatorio de Inmigración y Cooperación, 2009: 7), ofrece como resultado que son consumidores habituales de medios generalistas y de medios propios, por lo que complementan su consumo de manera conjunta. Según datos de la primera oleada del Estudio de Medios para Inmigrantes (EMI 2007)ํㅜ realizado en la Comunidad de Madrid, sólo "en esta región se ofertan más de 70 medios de comunicación, entre periódicos, revistas, webs, programas de televisión y radio y algunos medios dirigidos a este colectivo tienen un elevado grado de penetración, por encima de los gratuitos generalistas y de los diarios deportivos de pago" (El Publicista, 2008:183).

\section{El consumo de los medios por parte de los inmigrantes latinoamericanos}

La población inmigrante latina que reside en España consume diariamente medios generalistas y étnicos que cubren diversas necesidades, tanto informativas como de conocimiento de marcas. La publicidad que reciben sobre la diversidad de servicios y productos es valorada de forma positiva por este público, ya que la mayoría de marcas les resultan novedosas (Álvarez et al., 2009).

Según el EMI de 2007, en el conjunto de medios, los latinoamericanos presentan un consumo similar al público español, si bien los datos se concentran con arreglo a sus medios propios. De forma general, podemos señalar que:

- $\quad$ El latinoamericano comienza a ser un público habitual de la prensa gratuita generalista, pero especialmente consume prensa étnica.

El Estudio de Medios para Inmigrantes (EMI) del 2007 es un estudio realizado entre la población inmigrante de la Comunidad de Madrid para conocer el consumo de medios de comunicación entre este colectivo. Se trata de un universo de 629.903 de personas de todos los continentes. 
- $\quad$ Su consumo de radio es muy elevado, sobre todo en las fórmulas-musicales.

- $\quad$ En televisión presentan un consumo similar al de los españoles, en cuanto a que son espectadores diarios de la televisión generalista y cuentan con paquetes específicos de pago en Imagenio y Canal + Latinoamericano.

- Internet es un medio en claro crecimiento, especialmente para comunicarse familiares y amigos e informarse sobre productos, servicios y noticias de su país.

$\mathrm{Al}$ analizar su consumo de medios por sexo, se comprueba atendiendo a los datos que, según el EMI del 2007:

- $\quad$ Hombres y mujeres presentan consumos similares en medios escritos étnicos. Mientras las mujeres consumen más prensa gratuita generalista, los hombres destacan por ser ávidos lectores de prensa deportiva.

- $\quad$ Los hombres consumen más radio que ellas. Es un medio en el que ambos escuchan principalmente: música, noticias y deportes.

- También presentan consumos similares de televisión, aunque algo superior en las mujeres, sobre todo en programas de entretenimiento.

- Los hombres se conectan a Internet con mayor frecuencia que las mujeres, siendo sus principales usos: ver páginas web, correo electrónico y chatear.

- $\quad$ La franja de edad en la que ambos sexos consumen más medios se sitúa entre los 20 y los 34 años.

A continuación analizamos de forma más detallada el consumo de medios de los inmigrantes latinoamericanos según los datos del EMI de 2007.

En relación con la prensa, los latinoamericanos cuentan con una amplia oferta de publicaciones étnicas que ofrecen una gran diversidad de contenidos e información de utilidad para los inmigrantes que viven en nuestro país como temas de ocio, deportes, información legal, económica, etc. Respecto a las publicaciones semanales destaca el consumo de Latino, Sí se puede y El Comercio de Ecuador y si son mensuales tenemos que hablar de Ocio Latino, los medios del Grupo Raíz (Raíz Ecuador, Raíz Perú, Raíz Bolivia, Raíz Colombia, etc.) y Toumaï. La distribución es un elemento importante para hacer llegar estas publicaciones a su público. Así, los locutorios y el transporte (metro, autobuses, etc.) son los puntos de contacto más importantes que garantizan la entrega de estos medios (Etnia Comunicación, 2007/2008). Aunque los 
inmigrantes cuentan con un gran número de publicaciones, "son pocas las que tienen realmente un compromiso con una información de calidad y, en consecuencia, con el lector inmigrante” (Ríos, 2007: 110). Pese a que los medios escritos cuentan con la inversión de diferentes anunciantes, muchos deberían replantearse los contenidos y mejorar la información que destinan al público latinoamericano.

Respecto al medio radio, los latinoamericanos le dedican una media de 14,3 horas a la semana y destaca la cadena de los 40 Principales con el 25\% de menciones. A continuación aparece Kiss FM, con un $16 \%$ y Cadena Dial, con el 10\%. La mayoría de emisoras se encuentran en Madrid: Radio Mundial, Tentación, Pueblo Nuevo, Tropical, Fiesta FM, Hispana, Top Radio, Superestación Latina, entre otras, con una excelente acogida por parte de este colectivo, ya que la música tiene gran importancia para los latinoamericanos (Álvarez et. al., 2009). Estas emisoras tienen numerosos contenidos especializados, como es la información sobre los conciertos de artistas extranjeros en nuestro país. También algunas cadenas cuentan con espacios para los inmigrantes; así destaca La Cadena Ser con su magazín semanal de media hora Ser Latino y la COPE con el programa Sí se puede que se emite los sábados en Madrid (del periódico que lleva el mismo nombre).

Si nos referimos a la televisión, todavía la oferta es escasa, aunque encontramos en Cataluña ejemplos como Canal Latino TV, el primer canal de televisión destinado a los extranjeros que puede ser visto en 29 ciudades del país. Canal Plus Latinoamericano, paquete dirigido a casi dos millones de latinoamericanos que viven en España, incluye canales temáticos para diversos países: Ecuavisa para Ecuador, Caracol Televisión para Colombia, Canal de las Estrellas para México y Cubavisión para Cuba. En las televisiones generalistas también se emite programación específica para ellos, como son: Con todos los acentos, en TVE; Telenoticias sin fronteras y Latino, en Telemadrid; Andalucía sin Fronteras, de Canal Sur; Els Nous Catalans, en TVE de Cataluña y Nuevos Vecinos, de la Asociación de Televisión Educativa Iberoamericana. La programación dirigida al inmigrante, en medios propios y generalistas, cumple diversas funciones: proporcionar información sobre los temas de interés de estos colectivos, tanto en cuestiones legales como económicas, ocio, viajes, e información sobre España, como a nivel publicitario con las marcas y ofertas y promociones de productos, contribuyendo todo ello a la integración de esta población en el país.

Internet es un medio que el latinoamericano consume a diario, ya que utiliza la Red para obtener todo tipo de información. Según la Asociación para la Investigación de Medios de Comunicación (AIMC), los latinoamericanos son los inmigrantes que más lo utilizan, en torno a 200.000 usuarios, que representa el 18,9\% sobre el total. Entre los diferentes usos que Internet proporciona a los inmigrantes, señalamos que "la mayoría de los locutorios se ha sumado a esta tercera revolución y ha incorporado cámaras web a sus equipos informáticos, donde el inmigrante puede hablar y ver a sus familiares a través de programas como MSM o 
Skype, y servicios IP, como Talky" (VV.AA., 2007: 97). Internet es un medio muy económico que tiene una buena acogida en este colectivo, tanto por el volumen de información como por la rapidez y la capacidad de conexión. Además, permite a los inmigrantes establecer comunicación de voz e imagen con las personas de sus países de origen, por lo que ofrece un valor emocional añadido para ellos.

La evolución de los diferentes medios de comunicación que se está produciendo en nuestro país es posible porque existe un número suficiente de población para ser considerado como un público con demandas específicas tanto de productos y/o servicios como de información.

Los datos anteriormente expuestos constatan que la población inmigrante se está asentando en el país y que cuenta con una amplitud de medios en el mercado español, aunque todavía faltan publicaciones temáticas con mayor calidad en los contenidos y que ofrezcan una información completa adecuada a sus necesidades. Según un estudio realizado a la población inmigrante latinoamericana residente en la Comunidad de Madrid, las demandas informativas que tiene este público son: las que se relacionan con "problemas y preocupaciones existenciales que les afectan directamente como: legislación española de extranjería, trabajo, paro, vivienda, dinero y estudios (de naturaleza endógena) y las que tienen que ver con su integración social (de naturaleza exógena)” (Cardoso, De Francisco y Fernández, 2007: 117).

En definitiva, atendiendo a los diferentes estudios que permiten conocer los medios que se dirigen a los inmigrantes latinoamericanos, se puede asegurar que este mercado está en evolución y puede seguir creciendo en los próximos años creando nuevos soportes para este público y mejorando los existentes.

\section{La representación de los latinoamericanos en los medios.}

La inmigración ocupa los primeros puestos de preocupación entre los españoles en las encuestas del Centro de Investigaciones Sociológicas (CIS), que lo consideran año tras año como uno de los temas relevantes del país. Así, los españoles consideran “la inmigración” como el quinto problema por detrás del "paro", "los problemas de índole económica”, "el terrorismo” y "la vivienda” (Centro de Investigaciones Sociológicas, 2008: 8). Además, "existe entre la población la sensación generalizada de que los inmigrantes son una amenaza” (Rey, 2008: 135).

\subsection{Estereotipos de la población latina en los medios de comunicación}

Diferentes estudios aluden a la asociación negativa de los medios y los inmigrantes. Tal y como señala Casero, la prensa "fomenta la alarma social y magnifica el fenómeno de la inmigración apelando al peligro y a 
las consecuencias negativas, como es el incremento de la delincuencia y la inseguridad" (Casero Ripollés, 2005: 15). La percepción que existe del inmigrante entre la población española está relacionada con la imagen negativa que aparece en los medios y que tiene una repercusión en la opinión pública, ya que existe una relación directa entre la presencia mediática de los inmigrantes, el dramatismo de la entrada en España por parte del colectivo africano y las opiniones que reflejan los españoles sobre este colectivo.

España se ha convertido en estos últimos años en el segundo país del mundo que acoge un mayor número de inmigrantes, por lo que los medios deben mostrar más sensibilidad con este colectivo, ya que "la aceptación por parte de la opinión pública de la diversidad étnica viene determinada, en gran parte, por el papel que desarrollan los medios de comunicación de masas, a través de la transmisión y conformación de imágenes o representaciones de determinados colectivos sociales" (Muñiz e Igartua, 2004: 90). En este sentido, las diferentes asociaciones que se atribuyen a los inmigrantes por noticias de índole negativa se generalizan y se suelen aplicar a la mayoría, de forma que asociamos más las palabras como "narcotráfico, mafias o bandas" con los extranjeros (Rocal Ciriaco, 2006).

Los medios han sobredimensionado el fenómeno que incide en los discursos por parte del Estado para justificar la política restrictiva de ingreso de esta población (Pedone, 2001). En Europa el fenómeno de la inmigración se ve desde una ideología negativa y los inmigrantes tan sólo son vistos como un préstamo que tiene que ser devuelto, ya que las naciones europeas tienen la percepción de ser países perfectamente acabados, perfilados, compartiendo además el gusto de sentirse europeos (Pérez Sierra, 2002). Y así se refuerzan los estereotipos en la opinión pública con asociaciones del inmigrante como conflictivo, invasor, violento, enfermo o pobre, que favorecen la segregación del colectivo. El resultado es que "lo que se ha contado ha creado la imagen del inmigrante como persona desvalida y desesperada, que está dispuesta a todo para sobrevivir y, en consecuencia, que no es muy de fiar" (Ortega Dolz, 2004: 256). Estas simplificaciones germinan en el imaginario colectivo maquilladas de una peligrosa capa de legitimidad (Palladino, 2007).

Es incuestionable la responsabilidad de los medios en la configuración de la representación social del inmigrante y su influencia en la opinión pública. Tal y como recoge Van Dijk (Muñiz e Igartua, 2004: 88) "los inmigrantes, refugiados, minorías étnicas y otras poblaciones procedentes del Sur son asociados cada vez más en los medios de comunicación con las amenazas socioeconómicas y culturales, con la desviación, la delincuencia y la violencia”. Este es un aspecto que los inmigrantes denuncian reiteradamente porque los medios no reflejan su realidad de manera adecuada.

De modo que los inmigrantes suelen ser noticia generalmente por motivos relacionados con: delincuencia, pobreza, muerte, etc., conceptos que refuerzan la negatividad hacia ellos. Las noticias de los periódicos, 
radio y televisión buscan el impacto mediático, destacan generalmente noticias que generan una actitud de rechazo hacia este colectivo y, de esta forma, se consolida la imagen de la inmigración como problema (Rodríguez y Mena, 2008). Se confirma así la idea de que se vende en la prensa la información que más cotiza en el mercado noticioso (Retis, 2006).

Según el citado estudio de Muñiz e Igartua (2004) sobre el tratamiento informativo de la inmigración en España, los temas que son tratados habitualmente en las noticias sobre inmigración se relacionan en primer lugar con el control de las fronteras (con un 31,4\%), seguido a gran distancia de los avances en la convivencia (10,5\%), la lucha contra las mafias y el tráfico ilegal de inmigrantes (9,5\%) y las medidas de acogida (8,6\%). Estos cuatro temas engloban el $60 \%$ de las informaciones analizadas, "siendo más negativo el acercamiento a las informaciones sobre inmigración en televisión (60\%) que en la prensa (38,5\%)” (Muñiz e Igartua, 2004: 100).

En este estudio se comprueba también que los inmigrantes latinoamericanos reciben un trato más favorable y aparecen en noticias sobre las mejoras en la integración frente al tratamiento que reciben los africanos. Estos aparecen muy ligados a las imágenes de las pateras, cuyo impacto visual tiene la correlativa consecuencia de asociar a este colectivo con atributos que refuerzan la percepción de inferioridad del inmigrante.

Sin embargo, otros datos contrastan con las noticias que aparecen a diario en los medios, ya que menos del 1\% de los inmigrantes llega a España en pateras, según datos del Instituto Nacional de Estadística (INE) sobre Migraciones Exteriores del 2007. Aunque no existe una correlación directa entre las noticias y la realidad, los medios contribuyen a generar opinión pública condicionada, en este caso, por noticias que aluden sólo a una parte de la realidad de un determinado grupo dentro del gran colectivo de la población inmigrante que reside en España.

La utilización de estereotipos en los medios de comunicación, tanto en noticias como en programas de televisión y anuncios publicitarios, está supeditada a una realidad cultural construida a lo largo del tiempo que coloca al inmigrante latinoamericano generalmente en una posición de inferioridad con respecto a la población del país (Vázquez, 1999). Para cambiar esta percepción es necesario sensibilizar a los responsables de los medios para que ajusten sus modelos de representación a la realidad social de los inmigrantes y no se limiten a reproducir estereotipos anclados en conceptos culturales obsoletos.

El impacto mediático sobre las percepciones del público tiene consecuencias directas en la integración de los inmigrantes. Cabe preguntarse entonces cómo debería aparecer la población extranjera en los medios, desde una perspectiva que sea fiel a la realidad, para contrarrestar la percepción negativa que éstos fomentan y que tiene consecuencias de rechazo hacia este colectivo. 


\subsection{El uso adecuado del lenguaje y las imágenes en los medios de comunicación}

Los medios de comunicación tienen la responsabilidad de fomentar una percepción positiva de los inmigrantes, informando de manera más amplia sobre diferentes aspectos que habitualmente no aparecen en las noticias como: la realidad propia según las diferentes culturas de origen, las dificultades que encuentran en España para encontrar y mantener el empleo, las situaciones de discriminación que padecen por ser extranjeros, etc. De esta manera, se podrá dar una visión más amplia de su realidad y desterrar falsos estereotipos que un buen número de analistas coinciden en señalar ante la falta de objetividad en la percepción de este fenómeno social.

Las noticias deben elaborarse además con un lenguaje adecuado, ya que los medios no se limitan a informar, también sugieren cómo se han de interpretar las noticias de acuerdo a su ideología (Sendín Gutierrez, 2005).

Los medios construyen una realidad determinada, al tiempo que "proporcionan modelos de identidad y ejercen una poderosa influencia en las audiencias desde todos sus formatos, sea el informativo, el entretenimiento-espectáculo o la publicidad" (Ministerio de Trabajo y Asuntos Sociales, 2007: 9).

En la actualidad existen diferentes manuales de estilo con un desglose de recomendaciones a todos los agentes sociales que tienen una influencia en la construcción social de la imagen de los inmigrantes. En este sentido, los profesionales de la información audiovisual pueden contribuir a la mejora de la percepción del colectivo de inmigrantes teniendo en cuenta algunas recomendaciones, tales como las que se recogen en la "Guía práctica para los profesionales de los medios de comunicación. Tratamiento informativo de la inmigración”, que se resumen en: "tener en cuenta su punto de vista en la información, evitar el sensacionalismo en las noticias, así como cuidar el lenguaje empleado en los medios, fomentar la diversidad cultural o evitar el paternalismo" (Ministerio de Trabajo y Asuntos Sociales, 2007: 13).

También el “Manual de estilo periodístico para el tratamiento de las minorías étnicas” señala una serie de recomendaciones para que tanto las empresas periodísticas como las instituciones hagan un esfuerzo normalizador a la hora de tratar las informaciones que tienen como protagonistas a los colectivos inmigrantes, como por ejemplo, mediante "la difusión de valores positivos de las diferentes culturas que la configuran obviando los estereotipos y términos semánticos que sean susceptibles de perjudicar la valoración social de estas personas" (Colegio de Periodistas de Cataluña, 2006: 5).

El lenguaje y las imágenes que aparecen en los medios tienen la capacidad de modificar la percepción de la realidad. La imagen adecuada en las noticias, como la aparición de inmigrantes en series de televisión y 
anuncios publicitarios son, a su vez, una forma de normalización de este colectivo. Los medios deben reflejar y fomentar la diversidad que forma parte de la realidad española, en concordancia con los datos estadísticos y los diferentes estudios que demuestran que la inmigración es un fenómeno de importantes consecuencias en todos los ámbitos de la sociedad.

\section{Objetivos y metodología del estudio}

El presente artículo es el resultado de un proyecto de investigación ${ }^{2}$ más amplio encargado por la Asociación Española de Agencias de Publicidad (AEAP), cuyo planteamiento de estudio ha sido conocer los efectos que la publicidad ejerce sobre el colectivo inmigrante que reside en nuestro país.

Por tanto, los objetivos de investigación específicos a los que hemos dado respuesta en este artículo son los siguientes:

- $\quad$ Conocer los motivos por los cuales consumen los distintos medios de comunicación, tanto generalistas como específicos. Evaluar las diferencias y/o similitudes del consumo de medios en función de las variables sexo y edad. Estudiar la función que, para los inmigrantes, tienen los mensajes publicitarios que se insertan en los diferentes medios.

- Analizar cuáles son los medios preferidos para los inmigrantes a la hora de exponerse a la publicidad, así como las características que ésta tiene en función del soporte en el que se inserta.

El desarrollo metodológico seguido en el presente estudio se ha dividido en dos fases. La primera ha consistido en una investigación exploratoria (Bigné, 2000) cuyo objetivo era aproximarse al tema objeto de estudio: la inmigración y su relación con la publicidad. Para obtener esta información se realizaron los siguientes estudios que a continuación se detallan:

- Un estudio documental permitió una primera revisión de las diferentes fuentes secundarias existentes, lo que reveló, por un lado, la escasa existencia en la actualidad de estudios relacionados con la inmigración y la publicidad ${ }^{3}$ y, por otro lado, la necesidad de investigar al inmigrante desde un

2 El proyecto de investigación se titulo: “Publicidad e Inmigración”. El estudio se desarrolló desde abril a diciembre de 2008 por un equipo de investigadores formado por: Antón Álvarez, Sonia Carcelén, Belén López, Ana Sebastián y Nuria Villagra.

3 La mayoría de estudios que existen son de carácter cuantitativo y se centran en conocer al inmigrante o bien desde un punto de vista sociológico (estudios del INE, el Padrón o los realizados por la Consejería de Inmigración y Cooperación de la Comunidad de Madrid) 
enfoque profundo que nos aportará una mayor calidad de la información. Aún así, todas las fuentes consultadas nos han permitido comprender, tanto desde un punto de vista sociológico como económico, el fenómeno migratorio que ha experimentado nuestro país, así como su evolución y situación actual.

- Junto con la información recogida a través de las fuentes secundarias, se realizaron ocho entrevistas en profundidad a expertos ${ }^{4}$, conocedores de la situación de los inmigrantes y su relación con los medios de comunicación y la publicidad, durante los meses de marzo y abril de 2008, con el objetivo de completar la información secundaria con datos más actuales y de primera mano que nos aportaran una visión más rica y profunda de la publicidad y la inmigración en España.

- $\quad$ Por último, se realizó un análisis del contenido de las campañas gráficas, insertadas en prensa especializada $^{5}$, dirigidas al inmigrante latinoamericano aparecidas desde enero a junio de 2008. De esta manera, pudimos conocer los sectores más activos en publicidad dirigida a este target, así como los mensajes y tono más utilizados a la hora de conectar con ellos.

Con toda la información obtenida en la etapa exploratoria, se llevó a cabo una segunda fase del estudio que consistió en la realización de una investigación cualitativa basada en grupos de discusión a una muestra formada por inmigrantes latinoamericanos residentes en la Comunidad de Madrid por varios motivos:

- $\quad$ En primer lugar, por su peso estadístico, ya que constituye la comunidad inmigrante más numerosa en nuestro país. El colectivo latinoamericano representa el 39,5\% respecto del total de inmigrantes residentes en nuestro país (Observatorio de Inmigración, 2009: 78);

- $\quad$ en segundo lugar, porque la inmigración latina comparte con los españoles el idioma y una gran cantidad de lazos y valores culturales, lo que hace que se convierta en poco tiempo en un espectador pleno y consecuente de los medios de comunicación y sus mensajes publicitarios;

o como sujeto activo de consumo de marcas (como el Ómnibus de Inmigrantes que ofrece tanto Nielsen como ECV Investigación) o de medios (como el Estudio de Medios para Inmigrantes, EMI, que realizar AIMC y ECV Investigación o los Anuarios de la Comunicación del Inmigrante en España que ofrece ETNIA Comunicación).

4 Los ocho expertos consultados fueron: un consultor de comunicación, un responsable de una agencia de medios, dos responsables de marketing y comunicación de empresas anunciantes de sectores distintos, un responsable de un medio de comunicación especializado en inmigrantes latinoamericanos, un director de una agencia de publicidad especializada entre el colectivo inmigrante, el director del Observatorio de Inmigración de la Comunidad de Madrid y, un responsable de planificación estratégica de una agencia de publicidad de servicios plenos.

5 Los periódicos latinoamericanos consultados fueron: Latinoamericano, Sí se puede y Toumaï. 
- $\quad y$, en tercer lugar, este colectivo muestra un notable grado de homogeneidad en cuanto a sus variables sociodemográficas, económicas y culturales, por oposición a los demás grupos inmigrantes, lo que simplifica metodológicamente varios aspectos del estudio, principalmente el hecho de compartir el mismo idioma que facilita la realización de la investigación, soslayando complicados problemas idiomáticos que podrían desenfocar la aplicación de la metodología de estudio y, en consecuencia, los resultados de la investigación.

Se llevaron a cabo un total de 8 focus groups (compuestos por 10 personas cada grupo, por lo que la muestra total fue de 80 personas entrevistadas), segmentados por tres variables: sexo, edad y tiempo de permanencia en la Comunidad de Madrid, con el objetivo de conocer posibles diferencias significativas en función de cada una de ellas.

Respecto a la primera variable se separó a las mujeres de los hombres para que pudieran expresar con mayor libertad sus opiniones; en cuanto a la edad se seleccionó el intervalo entre los 16 y 38 años ya que constituye el de mayor peso y representatividad entre los inmigrantes latinoamericanos que residen en esta Comunidad diferenciando dos grupos: jóvenes y adultos; por último, nos pareció interesante segmentar por el "tiempo de residencia” para así conocer si las opiniones son las mismas para un inmigrante recién llegado (que lleva en España de 1 a 3 años) que otro que lleva más tiempo en nuestro país y se encuentra más integrado (de 4 a 8 años). A continuación se detallan los ocho grupos en función de las 3 variables de segmentación.

Tabla.1. Distribución de los Focus Groups en función de las variables de segmentación

\begin{tabular}{|c|c|c|c|c|c|}
\hline & & & úmero de a & esidencia & \\
\hline & & Ent & ños & Entr & años \\
\hline $\begin{array}{l}\text { Edad y } \\
\text { sexo }\end{array}$ & $\begin{array}{l}\text { Jóvenes adultos } \\
\text { de } 16 \text { a } 23 \text { años }\end{array}$ & $\begin{array}{l}\text { Hombres } \\
\text { (Grupo 1) }\end{array}$ & $\begin{array}{l}\text { Mujeres } \\
\text { (Grupo 3) }\end{array}$ & $\begin{array}{l}\text { Hombres } \\
\text { (Grupo 5) }\end{array}$ & $\begin{array}{c}\text { Mujeres } \\
\text { (Grupo 7) }\end{array}$ \\
\hline & $\begin{array}{l}\text { Mayores de } \\
24 \text { a } 38 \text { años }\end{array}$ & $\begin{array}{l}\text { Hombres } \\
\text { (Grupo 2) }\end{array}$ & $\begin{array}{l}\text { Mujeres } \\
\text { (Grupo 4) }\end{array}$ & $\begin{array}{l}\text { Hombres } \\
\text { (Grupo 6) }\end{array}$ & $\begin{array}{l}\text { Mujeres } \\
\text { (Grupo 8) }\end{array}$ \\
\hline
\end{tabular}

Fuente: Elaboración propia

El trabajo de campo se ha desarrollado únicamente en la Comunidad de Madrid, por ser la segunda comunidad autónoma más importante en cuanto al número de inmigrantes residentes (después de Cataluña) durante el mes de junio de 2008. 
Debido a la cantidad de información obtenida en la investigación, en este artículo explicamos la parte del estudio centrada en la relación de los inmigrantes latinoamericanos con los medios de comunicación y, en concreto, la información recogida en las entrevistas en profundidad y en los focus groups.

\section{Resultados del estudio}

\subsection{La visión del experto. Un consumo de medios específico y diferenciador.}

Los latinoamericanos que residen en España presentan un consumo de medios que se caracteriza por la utilización de forma complementaria tanto de los generalistas como de los étnicos. De manera específica, el uso que hacen de cada medio puede resumirse de la siguiente forma, tal y como describen los expertos entrevistados en esta investigación:

- Televisión: los inmigrantes presentan un comportamiento similar a los españoles en el prime-time de las cadenas generalistas. Además, cuentan con programación propia en televisiones públicas españolas y canales de pago de sus países.

- $\quad$ Radio: las radio-fórmulas latinas crecen y se consolidan en España como su medio preferido.

- $\quad$ Prensa: leen prensa gratuita generalista y prensa específica destinada a cada nacionalidad.

- $\quad$ Internet: es el medio que les permite principalmente comunicarse con familiares y amigos e informarse de los acontecimientos de sus países de origen.

De manera general, los latinoamericanos consumen todo tipo de medios, pero tienen un comportamiento específico que les caracteriza y les distingue de cualquier otro público, como se comprueba al analizar los diferentes soportes que eligen en el mercado.

A continuación, detallamos las opiniones de los expertos sobre en consumo de cada medio en particular.

\subsubsection{La televisión}

El colectivo latinoamericano tiene unas preferencias muy similares a la media española tanto en el consumo de televisión como en el nivel de penetración. Las diferencias que presentan se relacionan con los hábitos de ocio e inercias de trabajo que producen cifras algo distintas, ya que su consumo se complementa con canales específicos para inmigrantes donde buscan el entretenimiento que caracteriza a este medio. 
Los expertos señalan que las cadenas públicas españolas ofrecen contenidos específicos para los latinoamericanos que presentan una escasa penetración, ya que suelen ser programas de contenido social que utilizan un tono paternalista que no conecta con este público. Por el contrario, las televisiones de pago ofrecen gran variedad de programas que registran buenas cifras de audiencia porque cuentan con una amplia programación para cada una de las nacionalidades (mejicanos, peruanos, colombianos, etc.).

\subsubsection{La radio}

Todos los expertos coinciden en destacar que son grandes consumidores de este medio, especialmente de contenidos musicales más que de información, en comparación con el consumo de los españoles, donde destaca la tertulia de las emisoras generalistas. En los últimos cuatro años han aparecido un gran número de emisoras en España dirigidas de forma específica al público latinoamericano basadas en la radio-fórmula, en radios generalistas, como son: 40 Principales, Cadena 100, KissFM, Europa FM, o radios latinas: TopRadio, Pueblo Nuevo, Tentación, entre otras.

Pese a ello, abundan un gran número de radios piratas musicales que cuentan con un consumo importante entre el público latinoamericano. Éste es un fenómeno muy extendido, ya que tienen mucho seguimiento entre este colectivo, aunque no tienen un posicionamiento definido debido a su escasa cobertura.

La radio es un medio que llega a todos los latinoamericanos, independientemente del nivel cultural, económico y social, por lo que se convierte en un soporte muy extendido entre este público, puesto que es muy fácil de entender y puede combinarse con cualquier otra actividad además de ser compartido con otras personas.

\subsubsection{La prensa}

La prensa, por su parte, tiene una elevada penetración en este público, aunque el precio es un factor determinante. Los latinoamericanos consumen sobre todo prensa gratuita, ya que tiene una alta afinidad con este target y la encuentran fácilmente, sobre todo en la salida del metro, los CEPIS (Centros de Integración y Participación para Inmigrantes) y los locutorios. También se produce un ligero aumento del consumo de prensa española de pago; por lo que, teniendo en cuenta que es un público poco aficionado a la lectura, suelen complementarla con medios propios y periódicos españoles gratuitos.

En el mercado español existen multitud de soportes escritos dirigidos específicamente para inmigrantes, la mayoría de ellos son de carácter semanal y mensual y cuentan con información de su interés, especialmente la referida a su tiempo de ocio. En opinión de los expertos, estas publicaciones están segmentadas por nacionalidades, y han mostrado un importante crecimiento en España paralelo al de la población latina en estos últimos años. 
En la prensa étnica destaca el consumo del periódico Latino sobre los demás, debido principalmente a que utiliza un tono muy cercano al del público al que se dirige, sin llegar a ser paternalista, y es, por este motivo, por lo que ha conseguido un alto nivel de prescripción entre este target.

\subsubsection{Internet}

Internet destaca por ser un medio con un índice de penetración muy alto, aunque el uso es ligeramente inferior a la media española. Los expertos también señalan que tiene un alto valor sentimental entre este colectivo, ya que lo utilizan principalmente como un instrumento para comunicarse con otras personas, generalmente familiares y amigos, mientras que los españoles lo usan sobre todo para informarse y descargar archivos de diversa índole.

El alto consumo de Internet entre los latinoamericanos se debe, en primer lugar, a la propia accesibilidad de este medio, que les resulta económico y rápido en su utilización y, en segundo lugar, a que les permite estar al día y en contacto con la información y realidad de sus países. Sin embargo, a medida que estén más tiempo en España y se incorporen a puestos de trabajo cada vez más especializados, el uso de este medio cambiará haciendo que sea más imprescindible su utilización como una herramienta profesional.

Una vez comentadas las principales características que definen a los latinoamericanos en su consumo de medios, tal y como las definen los expertos entrevistados en esta investigación, podemos señalar que los medios de comunicación en España cubren diversas necesidades de los inmigrantes. Muestran diferentes motivaciones para exponerse a cada uno de ellos tal y como se recogen en la figura 1, a modo de resumen. 
Figura 1. Consumo de medios de la población latina en España

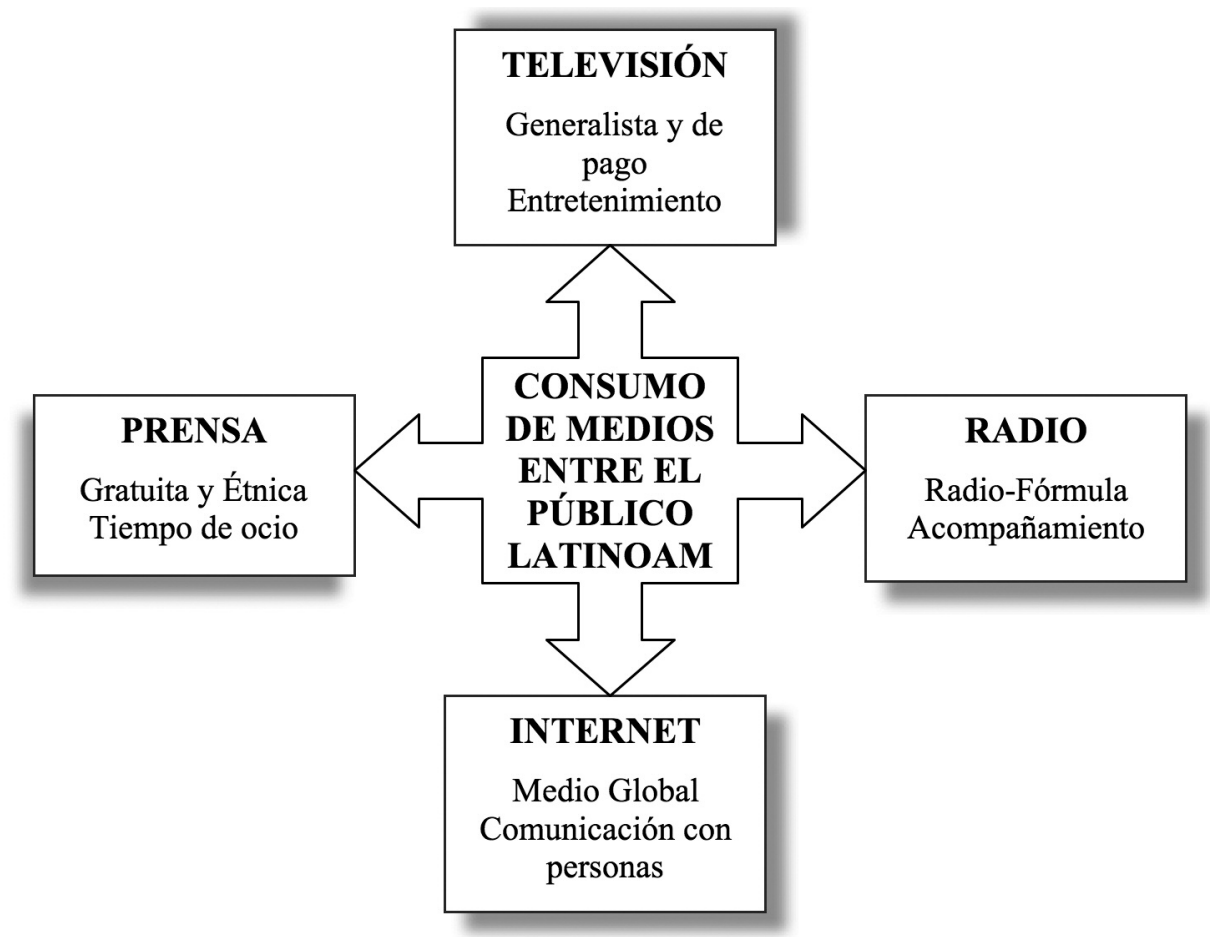

Fuente: Elaboración propia

\subsubsection{Relación entre los medios y la publicidad}

La mayoría de los expertos señalan que la publicidad dirigida a los latinoamericanos en España se caracteriza por la utilización de mensajes que generalmente excluyen a este colectivo de los medios masivos. Las marcas elaboran campañas específicas donde se destacan elementos tan recurrentes como: banderas de cada país, mensajes recargados de información, etc. (principalmente en prensa), pero que carecen de una estrategia común.

Por este motivo, los expertos inciden en que las marcas deberían evolucionar e incluir a los inmigrantes como público-objetivo más en sus campañas publicitarias. Así, una estrategia adecuada para dirigirse a este público estaría condicionada por el presupuesto asignado: 
Si el presupuesto es elevado, la televisión sería el medio más adecuado para posicionar las marcas, complementándose con mensajes específicos en medios propios: prensa, radio o Internet.

- $\quad$ Si el presupuesto no permite realizar una estrategia en medios convencionales, las promociones, eventos y acciones en el punto de venta resultarían la manera más directa y adecuada de contactar con ellos vinculando el consumo con momentos especiales.

La capacidad de influencia que tiene la publicidad varía en función del medio al que se expongan los inmigrantes. En general, el latinoamericano es un público que recuerda la publicidad, especialmente la que se inserta en televisión. De ella destacan su gran nivel de impacto; sin embargo, posee poco poder de prescripción entre este target al no tener tanta vinculación con él como la prensa o la radio.

La televisión generalista presenta algunos inconvenientes que hacen que no sea todavía un medio tan interesante para dirigirse a ellos de manera específica ya que se dirige a grandes audiencias y su inversión es excesivamente elevada. Se logra mayor efectividad cuando los mensajes se insertan en canales específicos para inmigrantes latinoamericanos, justificándose así la inversión en este medio.

Según los expertos, la estrategia que las marcas tendrían que seguir a la hora de dirigirse a este target debería basarse en un concepto de comunicación universal, independientemente del medio que utilice para difundirlo, ya sea generalista o específico, ya que el inmigrante se expone por igual a todos los medios a la vez. En este sentido, las marcas deberían evolucionar y emitir mensajes más integradores y coherentes en todos los medios.

En España algunas marcas están desaprovechando oportunidades al no utilizar mensajes más universales que involucren a los latinoamericanos, y prefieren desarrollar otras campañas específicas para este público separándolo de la estrategia general de la marca. Los expertos consultados creen que utilizar una propuesta de continuidad en los diferentes medios ofrece mejores resultados en términos de comunicación y posicionamiento de marca.

Por tanto, se trataría de mantener la conversación de los medios masivos de manera directa con los latinoamericanos en sus soportes específicos y así aprovechar el impacto generado en un primer momento en los medios generalistas.

En resumen, los expertos subrayan la importancia de establecer una estrategia marca que se traduzca de una manera determinada en función de cada medio: 
En medios generalistas: utilización de conceptos universales que incluyan a todos los públicos de la marca, sean o no inmigrantes.

- $\quad$ En medios específicos: adaptación de los conceptos universales al público inmigrante latinoamericano.

4.2. La visión del inmigrante. Percepción de los medios de comunicación la publicidad por parte de los latinoamericanos

\subsubsection{Preferencias de los latinoamericanos en el consumo de los medios.}

Los inmigrantes latinoamericanos consumen toda clase de medios de los que ofrece el mercado español, aunque si atendemos a las variables edad y sexo encontramos que existen algunas diferencias significativas. Así, podemos decir de manera general que la radio es un medio común a todos ellos; Internet está especialmente vinculado con el público joven independientemente del sexo; la televisión es un medio más consumido por las mujeres latinas; y la prensa gratuita por los hombres.

Respecto a la variable edad, los jóvenes latinoamericanos tienen un comportamiento semejante al de los españoles, ya que destaca su gusto por las nuevas tecnologías sobre el resto de los medios. Dicen estar expuestos a los medios de comunicación, especialmente -y por este orden- a Internet, prensa gratuita y televisión, esta última para ver series y retransmisiones deportivas. Utilizan Internet casi a diario para consultar páginas web, acceder a diferentes contenidos audiovisuales y para descargarse películas. Suelen participar en chats (especialmente a través de Messenger) para estar en contacto con su país de origen; como dice uno de los entrevistados "en Internet buscamos lo de allá, para informarnos de lo que está sucediendo y compararlo con lo de aquí”. Algunos utilizan chats específicos para inmigrantes latinoamericanos, entre los que mencionan el de Terra, y LatinChat. Por último, asisten de forma esporádica al cine ya que les resulta caro, no solo por la entrada sino por las compras inevitables que rodean a este acto social, tal y como relata uno de los miembros de los grupos “(...) entonces llevas $12 €$ para la entrada, y luego compras palomitas, la coca cola..., verla en casa es más económico”.

En relación con la variable sexo:

Los hombres latinoamericanos consumen todo tipo de medios en España: televisión, prensa, radio, Internet, etc., así como medios específicos para ellos, especialmente la prensa gratuita, donde obtienen información sobre los productos y servicios que son de su interés. La televisión es un medio que despierta su interés por el deporte y las noticias y utilizan la radio para escuchar música de sus países en emisoras propias. 
Las preferencias cambian si nos fijamos en los comentarios de las mujeres latinoamericanas, ya que relacionan la televisión con un medio que les hace compañía y asocian su consumo a un momento de evasión, según ellas es "ideal para desconectar de la actividad cotidiana y poder relajarse", "es tiempo de relax, cuando una llega a casa lo único que quiere es sentarse en el sillón y ver la tele” o "es nuestra compañía”.

Aunque los latinoamericanos muestran estas diferencias en relación a las variables de segmentación sexo y edad, a medida que aumenta su tiempo de residencia en España van desapareciendo y su consumo es más similar al del público español.

\subsubsection{La percepción de la publicidad en los medios}

Los latinoamericanos son sensibles a la publicidad que consumen en todos los medios, al tiempo que señalan la utilidad que encuentran en los anuncios dirigidos a ellos. Es un público que generalmente ve la publicidad con agrado y, aunque existen algunas diferencias en función de la variable sexo, podemos decir que todos, independientemente de la edad y el tiempo de residencia en España, recuerdan algunas campañas concretas que se insertan en los diferentes soportes. Es un público que valora positivamente la publicidad, tanto por su función informativa como por su capacidad para movilizar sentimientos, y que destaca como cualidad principal de los anuncios su capacidad de ser impactantes.

A continuación explicamos las diferencias más significativas en función de la variable sexo.

\subsubsection{Hombres}

Todos, independientemente de la edad y el tiempo que llevan residiendo en España, conocen muchos tipos de publicidad y destacan de forma generalizada la que encuentran en: televisión, folletos, exterior (en el metro, postes, autobuses), periódicos, camisetas, vallas, Internet y los móviles.

Tienen una percepción clara de la finalidad que cumple la publicidad, así como de los diferentes criterios que caracterizan cada medio y los tipos de mensajes que pueden encontrarse en los distintos soportes, por lo que tienen una noción muy definida de la publicidad y sus funciones. Este hecho se refuerza más en los grupos formados por persona más jóvenes (menores de 24 años).

Todos destacan la publicidad en televisión por encima de la que aparece en los soportes gráficos. Por este motivo, sus medios preferidos para verla son: en primer lugar, la televisión, que citan de forma unánime, seguida de Internet y los periódicos gratuitos. 
A continuación detallamos la percepción que el hombre latinoamericano tiene respecto a la publicidad que encuentra en cada medio:

A pesar de que la televisión es el medio que más les gusta para ver la publicidad, a veces se quejan de la saturación publicitaria y muestran cierto rechazo hacia los mensajes comerciales que aparecen en este medio.

- $\quad$ Muestran una mayor aceptación de la publicidad que aparece en la radio ya que, aunque existe un exceso de mensajes, muchos van dirigidos sólo a ellos: promociones de cantantes, discotecas latinas, agencias de viajes, etc.

- $\quad$ La publicidad en Internet les resulta en ocasiones incómoda, incluso la califican de interferencia (se refieren especialmente a los pop-ups). Aunque recuerdan de manera positiva algunas campañas virales que se han difundido por la red en el último año, consideran que la publicidad en este medio es intrusiva.

- $\quad$ Respecto a la publicidad en periódicos les parece sencilla e incluso en ocasiones un poco aburrida; sin embargo también les aporta información relevante para ellos, por lo que les parecen muy interesantes los anuncios que cuentan con un contenido informativo.

- $\quad$ La publicidad en vallas tiene que ser en su opinión impactante y recuerdan especialmente la que puede observarse en los estadios de fútbol.

Los hombres latinoamericanos recuerdan la publicidad que se inserta en todo tipo de medios, ya sea en específicos o generalistas; e incluso, atribuyen un papel diferente a la publicidad que se aleja de su función puramente comercial, es decir, aquella que sirve para sensibilizar al público. Y es ahí donde encuentran más sentido a la propia publicidad.

\subsubsection{Mujeres}

En el caso de las mujeres, el tiempo de residencia en nuestro país no constituye una variable significativa, pero si atendemos a la edad, encontramos algunas diferencias que a continuación explicamos.

En relación con los grupos de chicas más jóvenes (entre 16 y 23 años) manifiestan un alto interés y aceptación hacia la publicidad, ya que en general les resulta atractiva y recuerdan de forma espontánea un gran número de anuncios. Señalan numerosos medios donde ven publicidad como: autobuses, revistas, móviles, Internet, televisión, etc., pero en los que ellas perciben que existe más publicidad son, por orden de mayor a menor, los siguientes: televisión, Internet, radio y prensa. 
- $\quad$ En general, son más receptivas a la publicidad en televisión que a la ven en prensa, en opinión de muchas de las mujeres entrevistadas es más "dinámica, divertida, creativa, original”, "te cuenta una historia", "te sientes más identificado, tiene que ver con tu vida” o "te llama más la atención, hace que te guste más... Como que tiene su magia”. Por este motivo, se sienten más identificadas con los mensajes publicitarios que aparecen en televisión y sienten que les impulsan más a comprar el producto que aparece en los spots. Por todo ello, señalan la televisión como el medio que les parece más llamativo.

- $\quad$ Internet es un medio al que también prestan especial atención y al que cada vez otorgan una mayor importancia debido a que pueden buscar específicamente lo que quieren. Internet les permite comparar y adquirir los productos a un precio más económico, chatear y ver publicidad. Para las jóvenes constituye un medio ideal a través del cual adquieren información y publicidad de su país.

- $\quad$ También la radio es un medio que les gusta porque les permite realizar tareas del hogar mientras escuchan su publicidad.

- $\quad$ Por último, aunque dicen ver bastante la publicidad que aparece en los periódicos gratuitos, no destacan nada significativo al respecto.

Si atendemos a las preferencias de las mujeres de mayor edad (de 24 a 38 años) manifiestan que los medios en los que ven más publicidad son: televisión, radio, exterior (vallas, marquesinas, carteles dentro del metro), folletos, prensa e Internet. En general tienen una percepción muy positiva de la publicidad española, sobre todo en televisión, ya que consideran que les atraen mucho los elementos que conforman el propio mensaje y porque es la más impactante con respecto al resto de los medios.

A continuación detallamos sus opiniones respecto a la publicidad asociada a cada medio:

Son más receptivas a la publicidad en televisión porque consideran que es más dinámica y les llama mucho la atención en comparación con la que están acostumbradas a ver en sus países de origen. La publicidad española les parece muy creativa y de mayor calidad, así lo relata una de las mujeres entrevistadas: "yo creo que aquí se gastan más dinero, hay más efectos especiales y salen actores superfamosos". Valoran positivamente que la publicidad refleje elementos como: el sol o los colores, que sea divertida o contenga elementos de humor, convincente, con argumento, que tenga acción, apele a los sentimientos y sea veraz. Los sectores de publicidad a los que prestan más atención son: perfumes, coches y belleza. 
- $\quad$ En relación con la publicidad en prensa, les resulta menos divertida que la que aparece en otros medios. Mientras que la publicidad en televisión es espectacular, la que encuentran en la prensa está muy relacionada con anuncios sobre promociones y donde el precio es un elemento muy recurrente, "en el periódico lo primero que te van a enseñar es el precio y con el precio va la promoción y luego las características del producto" explica una de las personas entrevistadas. Creen que se podría mejorar su creatividad y no centrarse únicamente en aspectos informativos, como el precio o características técnicas del producto. Citan mucha publicidad que aparece en la prensa gratuita y que normalmente suelen ver cuando usan el transporte público.

- $\quad$ A su vez, estas mujeres valoran positivamente Internet como un medio completo y con grandes posibilidades, "Internet supera a todo, porque lo tiene todo" comenta una de las mujeres de uno de los grupos. Además les permite acceder directamente a los contenidos publicitarios que son de su interés.

- $\quad$ También les gusta mucho la publicidad de folletos que editan sobre todo las grandes superficies, aunque consideran que es muy recargada y monótona.

- Internet es un medio que utilizan mucho, sobre todo para buscar productos concretos que necesitan en ese momento.

4.2.3. Tipo de publicidad que busca el latinoamericano en los medios

Los latinoamericanos se exponen a la publicidad de los medios con diferentes objetivos en relación a la información que obtienen en cada uno de ellos:

- $\quad$ En televisión consiguen información de las marcas y buscan ante todo que los anuncios sean impactantes.

- La radio les aporta información sobre múltiples eventos para su tiempo libre, como son los conciertos de música y fiestas.

- $\quad$ En prensa destacan las promociones de los productos que consumen habitualmente.

- $\quad$ En Internet buscan los productos de sus países para compararlos con los precios en España.

- $\quad$ Otros soportes, como son: vallas, metro, folletos, móviles, etc. cuentan con información de productos y marcas para este target.

La figura 2 resume la publicidad que consumen los latinoamericanos en los distintos medios. 
Figura 2. La publicidad que consumen los latinoamericanos en los medios

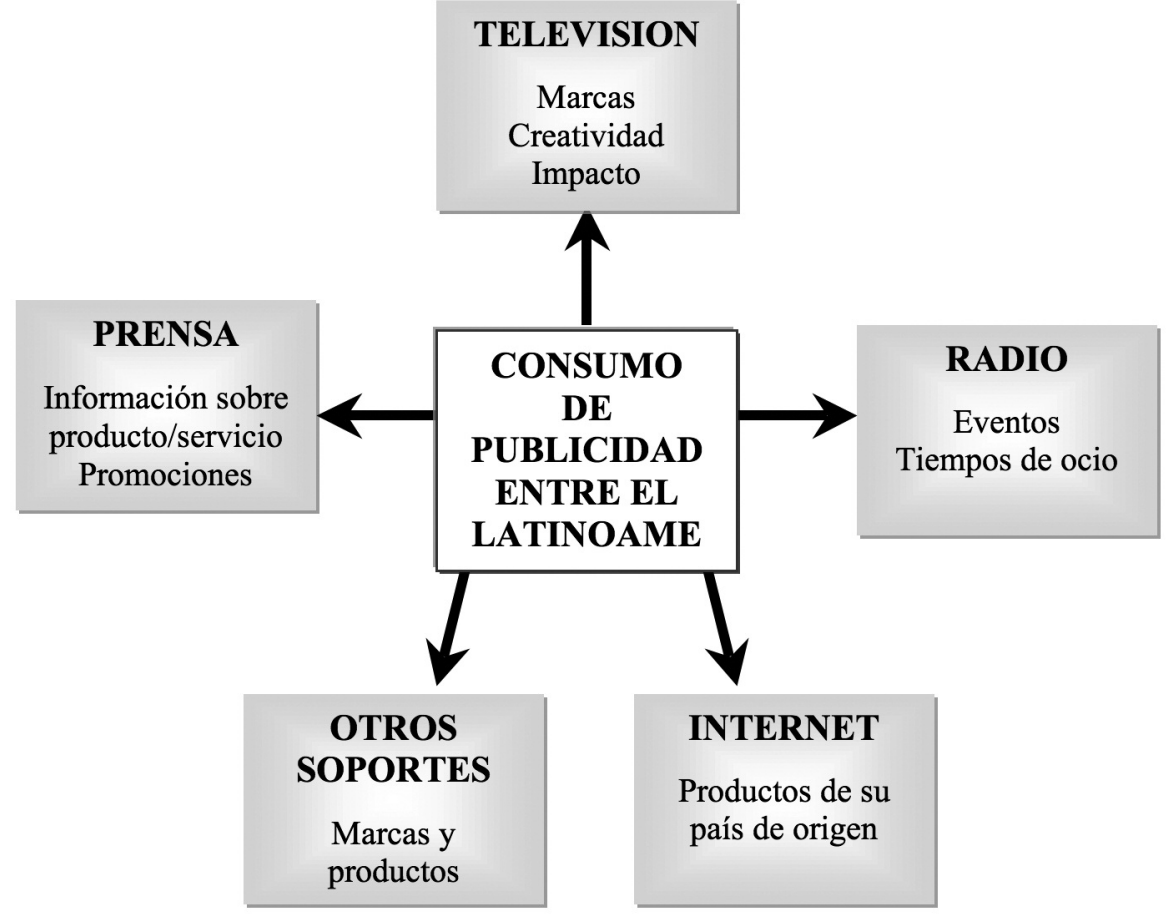

Fuente: Elaboración propia

\section{Conclusiones}

Las principales conclusiones del estudio, teniendo en cuenta tanto la visión de los profesionales entrevistados como la de los latinoamericanos estudiados, son:

- Los inmigrantes latinoamericanos que residen en España consumen todo tipo de medios, aunque difieren en algunos aspectos con respecto a la población española. Por un lado, consumen medios generalistas, principalmente televisión y prensa gratuita y, por otro lado, destaca la prensa y radio en medios especializados. 
Si atendemos al tipo de medios, podemos decir que la radio es un medio común a todos ellos, Internet está especialmente vinculado con el público joven e independientemente del sexo, mientras que la televisión es un medio más consumido por las mujeres latinoamericanas y la prensa gratuita por los hombres.

- Los jóvenes latinoamericanos tienen un comportamiento similar en cuanto al consumo de medios con respecto al de los españoles de la misma edad, ya que destaca su gusto por las nuevas tecnologías con respecto al resto de los medios.

- $\quad$ La televisión es un medio que consumen muy frecuentemente tanto los hombres como las mujeres latinoamericanas, aunque el uso que le dan al mismo es diferente. En el caso de los hombres, fundamentalmente para ver deportes e información y, en el caso de las mujeres es una forma de evasión y entretenimiento.

- $\quad$ En general, el tiempo de residencia es una variable que indica que a medida que llevan más tiempo residiendo en España, su consumo de medios se asemeja al de los ciudadanos españoles.

- El público latinoamericano valora positivamente la publicidad española y recuerda un buen número de anuncios cuando se refieren a ella. Las mujeres latinas son más receptivas al mensaje publicitario y lo aceptan con mayor agrado que los hombres.

- $\quad$ La televisión es para todos la forma preferida para ver publicidad y destacan su creatividad y su nivel de impacto, sobre todo si la comparan con la que se realiza en sus países de origen.

- $\quad$ En general, existe poca publicidad española dirigida a este colectivo en medios generalistas. Las marcas que deciden realizar campañas específicas para ellos, suelen utilizar códigos de comunicación muy recurrentes (como la utilización de banderas de sus países, colores muy llamativos, mensajes muy recargados de información, etc.).

\section{Recomendaciones estratégicas}

A la vista de los resultados obtenidos debe señalarse, como en cualquier otro público, que a la hora de definir la forma de llegar a este colectivo una marca debe tener muy en cuenta sus objetivos y el target al que se va a dirigir. Sin embargo, y a modo de indicación podemos decir que la estrategia de comunicación más conveniente que podrían seguir las marcas a la hora de dirigirse al inmigrante latinoamericano en los diferentes medios de comunicación debería cuidar los siguientes aspectos: 


\subsection{Publicidad especializada en medios específicos}

Este es sin duda un modo directo, muy relevante y de menor precio para llegar a ellos. Segmenta muy bien al público y posee una gran pertinencia y credibilidad. La estrategia de comunicación y, por tanto, la publicidad que tendrían que realizar las marcas en los medios específicos debería ser diferente en función de:

- Si existe un conocimiento previo de la empresa/marca por parte del inmigrante latino, ya sean marcas de su país de origen (Nativo, Fioravanti, etc.), o marcas internacionales (Coca-Cola, Vodafone), la publicidad debería potenciar la imagen de marca, para recordarles que el producto también lo pueden adquirir en España.

- Cuando el inmigrante no conoce ni la empresa ni los productos que ésta comercializa, como las marcas españolas (Cola-Cao, Nocilla, etc.), sería más recomendable realizar una comunicación informativa centrada en explicar los beneficios o características esenciales del producto, con el objetivo de crear un posicionamiento de marca. Así el latinoamericano sabrá qué marcas son del país, para qué sirven, y qué ventajas ofrecen, con el fin de que puedan consumirlas como el resto de españoles. El anuncio debería ser coherente con la estrategia global de la marca y puede realizarse una pieza específica si se refiere a alguna oferta o servicio especialmente dirigido a ellos. Sin embargo, debe señalarse que esto no es imprescindible si el mensaje emitido es universal.

En este apartado destacan, fundamentalmente, la prensa y revistas de sus países y la radio. Estas acciones se pueden completar con otras estrategias de below the line como acciones promocionales o eventos en sus lugares de reunión y encuentro (partidos de fútbol, CEPIs, parques, etc.)

\subsection{Publicidad universal e integradora en medios generalistas}

Tanto las marcas internacionales que son conocidas por los inmigrantes (Coca-Cola, Vodafone, etc.) como las nacionales que no conocen (Pascual, etc.) deberían realizar una comunicación global y universal para los españoles y los latinoamericanos. Si realizan campañas informativas porque están lanzando un producto que es nuevo para todos, será preciso informarles de la misma manera. Si el objetivo es reforzar su imagen de marca el anuncio también debería transmitir los mismos valores. Al igual que ocurre con otros públicos, los inmigrantes son sensibles a los distintos medios pero quizás debería destacarse que las acciones que más conectan con ellos son la televisión y la prensa gratuita. Internet es un medio con enorme potencial en el medio plazo. 
La publicidad que realicen las marcas no conocidas para los latinoamericanos en medios generalistas debería ser igual que para los españoles. Al igual que en la estrategia de medios específicos, en este apartado debe destacarse la pertinencia de llevar a cabo acciones below the line ya que son especialmente sensibles a las acciones en el punto de venta (promociones, degustaciones, PLV, etc.), folletos, street marketing, etc. Tal y como ocurre en los medios convencionales, estas iniciativas tienen una doble función: conectar emocionalmente con ellos e informarles sobre las características de los productos o servicios que comercializa la marca para que puedan construir un posicionamiento de las mismas.

Es conveniente resaltar que una marca desconocida sea internacional o nacional, que muestre en su comunicación personajes de diferentes nacionalidades y utilice "valores universales", puede ser considerada multicultural. Además, mostrar esa diversidad en la publicidad es una manera de expresar de forma natural la realidad social existente en España y de lograr una mejor y más rápida integración de los inmigrantes que viven en nuestro país.

\section{Referencias bibliograficas}

Álvarez, A.; Carcelén, S.; López, B.; Sebastián, A. y Villagra, N. (2009): Publicidad e Inmigración, Madrid: Asociación de la Comunicación Publicitaria (ACP).

Asociación para el Conocimiento de la Población Inmigrante, ACPI (2008): Estudio de Medios para Inmigrantes. Disponible en Internet [URL] http://www.acpi-emi.com/emi

Asociación para el Conocimiento de la Población Inmigrante, ACPI (2007): Estudio de Medios para Inmigrantes. Disponible en Internet [URL] http://www.acpi-emi.com/emi

Bigné, J.E. (2000): “Etapas del proceso metodológico en la investigación comercial”, en Martínez Gastey J. (coord.): La investigación en Marketing. Barcelona: AEDEMO, pp.123-138.

Cardoso, J.; De Francisco, J.A.; y Fernández, V. (2007): “Las demandas informativas de los inmigrantes latinoamericanos en la Comunidad de Madrid”, Doxa Comunicación, n 5, pp. 99-120.

Casero Ripollés, A. (2005): “Conflicto, noticias e inmigración: construyendo una identidad excluida”, Departamento de Periodismo y Comunicación Audiovisual, Universidad Pompeu Fabra. Disponible en Internet [URL]

http://www.portalcomunicacion.com.

Centro de Investigaciones Sociológicas (2008): Barómetro de abril no 2.761. Disponible en Internet [URL] http://www.cis.es

Colegio de Periodistas de Cataluña (2006): "Manual de estilo periodístico para el tratamiento de las minorías étnicas", en VV.AA.: Inmigración y medios de comunicación. Manual recopilatorio de buenas prácticas periodísticas, Bilbao: Harresiak, pp. 5-12. 
El Publicista (2008): “Inmigrantes: Medios para conseguir el impacto”, El Publicista, no 183, pp.32-34.

Instituto Nacional de Estadística, INE (2008): Padrón Municipal de enero de 2008. Disponible en Internet [URL] http://www.ine.es

Instituto Nacional de Estadística, INE (2007): Estadística sobre Migraciones Exteriores de 2007. Disponible en Internet [URL] http://www.ine.es

Muñiz, C. e Igartua, J.J. (2004): “Encuadres noticiosos e inmigración. Un análisis de contenido de la prensa y televisión españolas”, ZER, no 16 , pp. 87-104.

Observatorio de Inmigración y cooperación de la Comunidad de Madrid (2009): Informe de la población extranjera empadronada en la Comunidad de Madrid. Disponible en Internet [URL] http://www.madrid.org

Ortega Dolz, P. (2006): “La inmigración re-contada”, en Lario Bastida, M. (coord.): Medios de comunicación e inmigración. Murcia: Caja de Ahorros del Mediterráneo, pp. 253-272.

Palladino, J.P. (2007): “El tratamiento informativo de la inmigración en los medios”, Teína Revista electrónica de cultura y sociedad, no 15. Disponible en Internet [URL] http://www.revistateina.com

Pedone, C. (2001): "La inmigración extracomunitaria y los medios de comunicación: la inmigración ecuatoriana en la prensa española”, Scripta Nova Revista Electrónica de Geografía y Ciencias Sociales, no 94: Universidad de Barcelona. Disponible en Internet [URL] http://www.ub.edu/geocrit/nova.htm

Pérez Sierra, C. (2002): "Algunos estereotipos sobre la inmigración. El ejemplo de Madrid”, Anales de Geografía de la Universidad Complutense, no 18 (vol. extraordinario), pp. 387-398.

Retis, J. (2006): “La construcción social de la inmigración latinoamericana. Discursos, imágenes y realidades”, Amérique Latine Histoire et Mémoire, no 12, pp. 75-97.

Rey, J. (2008): “Publicidad e inmigración. Nuevas estrategias para un nuevo target”, Telos Cuadernos de Comunicación e Innovación, no 76 , pp.133-141.

Ríos, A. (2007): "Inmigración y medios de comunicación. Los latinoamericanos impulsan los mercados editorial y audiovisual de España”, Telos Cuadernos de Comunicación e Innovación, n 71, pp. 108-111.

Roncal Ciriaco, P. (2006): “Tratamiento informativo en televisión de la inmigración hacia España”, Sala de Prensa, nº 89. Disponible en Internet [URL] http://www.saladeprensa.org

Rodriguez Díaz, R. y Mena Montes, N. (2008): “Opinión Pública y frames: La crisis de los cayucos”, Revista Latina de Comunicación Social, no 63. Disponible en Internet [URL] http://www.ull.es/publicaciones/latina/

Sendín Gutierrez, JC. y Izquierdo Iranzo, P. (2007): Guía práctica para los profesionales de los medios de comunicación. Tratamiento informativo de la inmigración, Madrid: Ministerio de Trabajo y Asuntos Sociales. Secretaría de Estado de Inmigración y Emigración. 
Sendín Gutierrez, J.C. (2005): “Inmigrantes reflejados: una visión desde los medios de comunicación”, Pueblos Revista de Información y Debate, $\mathrm{n}^{\circ}$ 17. Disponible en Internet [URL] http://www.revistapueblos.org

Vázquez Aguado, O. (1999): “Negro sobre blanco: inmigrantes, estereotipos y medios de comunicación”, Comunicar, nº 12, pp. 55-60.

VV.AA. (2008): III Anuario de la Comunicación del inmigrante en España 2008/2009, Madrid: Etnia Comunicación.

VV.AA. (2007): II Anuario de la Comunicación del inmigrante en España 2007/2008, Madrid: Etnia Comunicación. 
